\title{
Correlation of perineal ultrasound and lateral chain urethrocystography in the anatomical evaluation of the bladder neck
}

Received: 26 March 2002/ Accepted: 27 May 2003/Published online: 20 November 2003

(C) International Urogynecological Association 2003

\begin{abstract}
Although perineal ultrasound has been widely used, no standard values have been published. In 52 women with urinary stress incontinence the following parameters were measured during resting and straining: a) with ultrasound: distance $\left(D_{y}\right)$ between bladder neck and central line of the symphysis, distance $\left(D_{x}\right)$ between bladder neck and lower border of the symphysis, and retrovesical angle $\beta$; b) with urethrocystography (UCG): distance $\mathrm{H}$ between the bladder neck and the SCIPP line, inclination angle $\alpha$ and retrovesical angle $\beta . \mathrm{D}_{\mathrm{y}}$ and $\mathrm{H}$ correlated during resting $(r=0.608 ; p<0.001)$ and straining $(r=0.575 ; p<0.001)$. The distance $\mathrm{D}_{\mathrm{y}}$ of $11 \mathrm{~mm}$ corresponded to a bladder neck position on the SQIPP line. A rotational descent was detectable when $\mathrm{D}_{\mathrm{x}}$ increased from $13 \mathrm{~mm}( \pm 6.5)$ during resting to $16 \mathrm{~mm}( \pm 7.8)$ during straining $(p=0.009)$. It was concluded that perineal ultrasound is valuable for the anatomical evaluation of the bladder neck. This is the first report to better define the position of the bladder based on ultrasonographic measurements.
\end{abstract}

Keywords Bladder neck - Incontinence $\cdot$ Perineal ultrasound · Urethrocystography

Abbreviations $U C G$ Urethrocystography $\cdot U C P R$ Urethral closure pressure $\cdot U S$ Ultrasound

\section{Introduction}

The position of the bladder neck in the pelvis is important for urinary continence. The investigation of the anatomy of the urethrovesical junction during urody-

C. Troeger · M. Gugger · W. Holzgreve · E. Wight $(\bowtie)$

Department of Obstetrics and Gynecology,

University of Basel, Schanzenstrasse 46,

4031 Basel, Switzerland

E-mail: ewight@uhbs.ch

Tel.: + 41-61-3259332

Fax: + 41-61-3259359 namic examination is essential to correctly diagnose pelvic floor insufficiency, which is fundamental for choosing the proper surgical management. Besides clinical examination two radiological methods, such as lateral bead chain urethrocystography (UCG) and perineal ultrasound (US) are used to visualize the relevant anatomical structures in the pelvis in an objective and reproducible manner [1]. These methods allow us to measure the localization and mobility of the bladder neck and to visualize compartments that are not accessible to gynecologic examination. Thereby, the pre- and post-therapeutic status can be documented objectively. Depending on the anatomical and urodynamic findings, the appropriate treatment can be selected [2].

For the routine evaluation of the bladder neck US has replaced UCG. Irradiation is the major disadvantage of UCG. In addition, US rather than UCG permits repeated and more dynamic examination of the morphology and function of the bladder and its surrounding structures $[3,4]$. The interobserver variation has recently been described as small [5]. However, it has lately been claimed that exact measurements of structures such as the pubic bone are difficult to obtain $[5,6]$, as they depend on various factors such as posture [7], bladder volume [8] and movement of the transducer [6]. It has been questioned whether US would be sensitive enough to predict genuine stress incontinence [9]. Significant bladder neck mobility has been demonstrated even in continent nulliparous women, as well as a relevant overlap in parameters obtained from continent and incontinent women [10]. More data are needed to correlate the sonographic findings of vertical and rotational hypermobility of the bladder neck with the clinical symptom of involuntary loss of urine. This question, however, can be answered by direct comparison of parameters of the 'new' US with those of the former 'gold standard' UCG. We were interested to correlate the height of the bladder neck measured by ultrasound with the corresponding distance of the bladder neck to the SCIPP line (sacrococcygeal inferior pubic point) in the UCG. 


\section{Material and methods}

Fifty-two patients aged 27-81 (mean 53.6) years, referred to our urodynamic outpatient clinic for evaluation of their urinary incontinence, underwent routine urethrocystography and perineal ultrasound. Both appointments took place within 2 weeks. Twenty-seven of the 52 women were postmenopausal. Parity ranged between 0 and 6 (median 2). Urodynamic measurements were performed in all 52 patients, including cystometry and urethral pressure profiles at rest and on straining in the supine and erect positions (SEDIA SE $>8$, Sedia AG, Givisiez, Switzerland). Half of the women proved to have genuine stress incontinence $(n=26)$, whereas others had combined stress and urge incontinence $(n=24)$ or incontinence secondary to neurological disorders $(n=2)$. As an indicator of transmission of the abdominal pressure to the urethra with straining we have used the depression quotient (DepQ) at the proximal third of the urethra. According to Eberhard [11], this quotient is calculated as DepP/UCPR (Fig. 1). A decrease in urethral closure pressure (UCPR) with straining was noted as a negative value (-DepP), whereas an increase was positive (+ DepP).

Urethrocystography was performed as described earlier [12]. Briefly, a lateral image was taken in the upright position with $60 \mathrm{ml}$ of water-soluble contrast medium in the bladder and a bead chain marking the urethra. An examiner unaware of the ultrasound results determined the following parameters according to Green [12] (Fig. 2): the vertical distance $\mathrm{H}$ of the internal urethral os to the SCIPP line, the angle of inclination $\alpha$ and the retrovesical angle $\beta$.

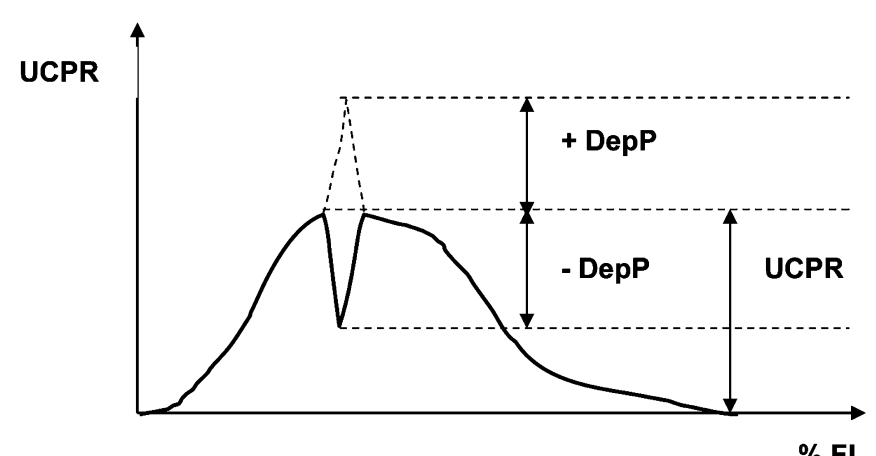

Fig. 1 Calculation of the depression quotient DepQ as a relation between the depression pressure DepP and the urethral closure pressure UCPR. DepP is negative when the UCPR is decreasing with straining and positive when it is increasing
These parameters were obtained at rest and on straining (Valsalva maneuver). In addition, a cystocele, funneling, vertical and/or rotational descent were documented.

The corresponding parameters were determined using perineal ultrasound in the upright position according to the guidelines published recently [8]. A $5 \mathrm{MHz}$ curved probe (Hitachi EUB-415, Glattbrugg, Switzerland) was placed on the perineum in a sagittal orientation to obtain an image of the symphysis, bladder, bladder neck and urethra. The bladder neck was identified without a catheter in place with a mean bladder volume of $383.3 \mathrm{ml}$ $( \pm 140.6 \mathrm{ml})$ after cystometry. Corresponding parameters were measured at rest and on straining (Valsalva maneuver), respectively: the distance of the internal os to the central line of the symphysis $\left(D_{y}\right)$, the distance of the internal os to the lower border of the symphysis $\left(D_{x}\right)$, and the retrovesical angle $\beta$ [8]. As with $\mathrm{UCG}$, the presence of a cystocele and funneling was notified.

The results of urethrocystography and perineal ultrasound were compared using Pearson's coefficient of correlation. Comparison of grouped variables (e.g. between rest and straining within patients) was performed using Wilcoxon's signed-ranks test. To measure the agreement between both methods in defining a cystocele or funneling, Cohen's $\kappa$ was used. For all calculations the Statistical Package for Social Sciences (SPSS for Windows 10.0; SPSS Inc., Chicago, IL) was applied. Any $p$ value $<0.05$ was considered significant.

\section{Results}

The ultrasonographically determined distance of the internal urethral os to the central line of the symphysis $\left(D_{\mathrm{y}}\right)$ correlated well with the distance $\mathrm{H}$ measured by UCG for both conditions, both at rest $(r=0.608$; $p<0.001)$ and during straining $(r=0.575 ; p<0.001)$ (Fig. 3). Accordingly, a height $\mathrm{D}_{\mathrm{y}}$ of $11 \mathrm{~mm}$ corresponded to a bladder neck located on the SCIPP line. Values above this level were defined as a high position of the bladder neck; conversely, values below $11 \mathrm{~mm}$ represented a low position. The height $\mathrm{D}_{\mathrm{y}}$ during straining correlated significantly with the pressure transmission defined as DepQ $(r=0.46 ; p=0.001)$ (Fig. 4). The mean bladder neck descent $\Delta \mathrm{H}$ determined by UCG was $19.1 \mathrm{~mm}( \pm 10.2 \mathrm{~mm})$. The measurements of the retrovesical angle $\beta$ determined with US and UCG at rest $(r=0.354 ; p=0.011)$ and during straining $(r=0.459$; $p=0.001)$, respectively, correlated well. The presence of a radiologically verified cystocele $(n=15)$ was confirmed
Fig. 2 Parameters measured by UCG (distance $\mathrm{H}$ between the internal urethral os and the SCIPP line, angle of inclination $\alpha$, retrovesical angle $\beta$ ) and by US (distance $\mathrm{D}_{\mathrm{y}}$ between the internal urethral os and the central line of symphysis, distance $D_{x}$ between the internal urethral os and the lower border of the symphysis,retrovesical angle $\beta$ )

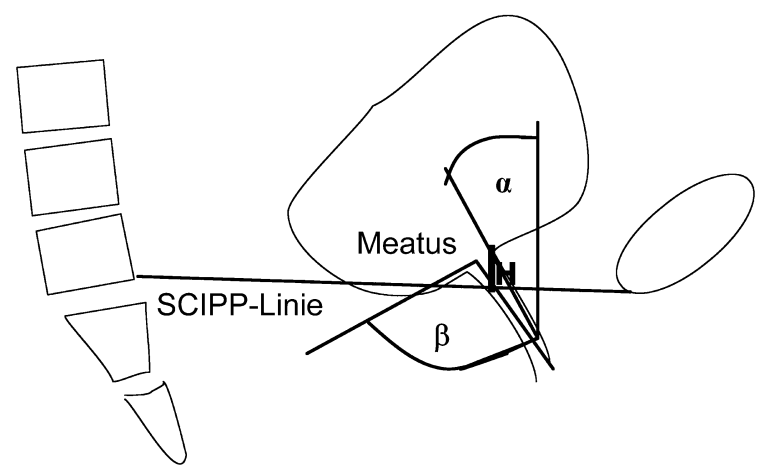

UCG

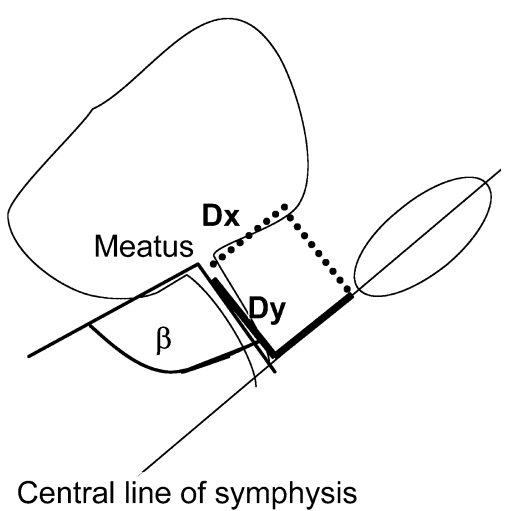

US 


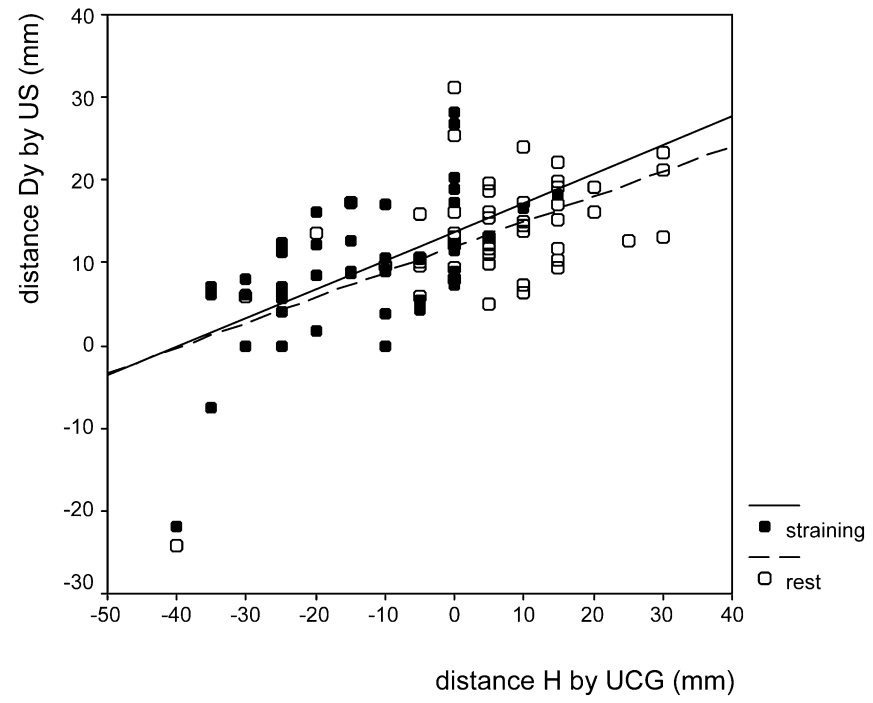

Fig. 3 Significant correlation between the distance $\mathrm{H}$ obtained by UCG and distance $D_{\mathrm{y}}$ measured by perineal ultrasound at rest $(r=0.608)$ and straining $(r=0.575)$

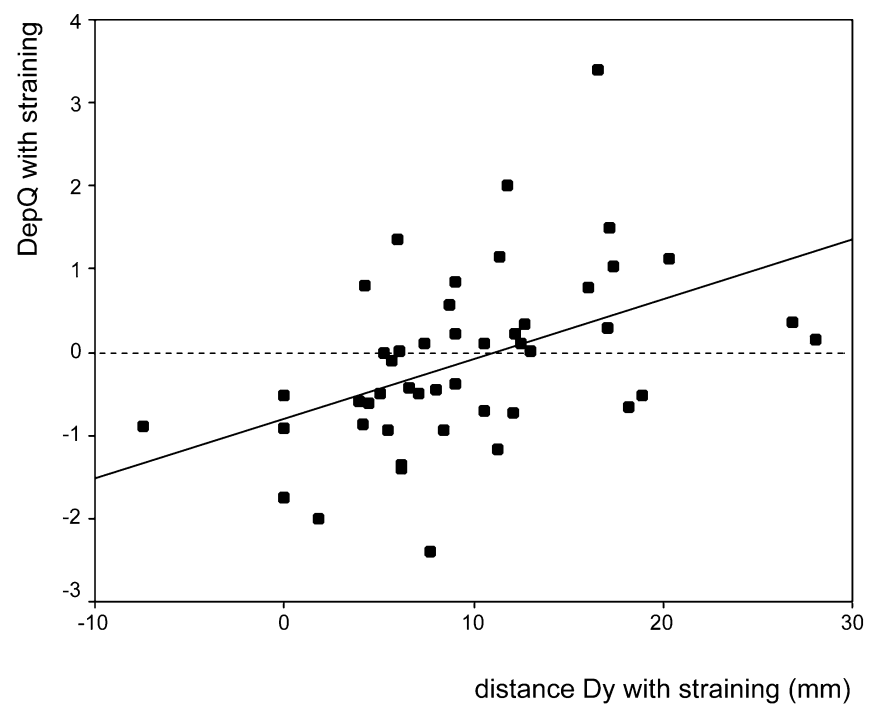

Fig. 4 Significant correlation between the distance $D_{y}$ with straining measured by perineal ultrasound and the pressure transmission defined as DepQ by urethral pressure profile with straining $(r=0.46)$. The reference line indicates the border between positive and negative DepP

Table 1 Agreement between ultrasound (US) and urethrocystography (UCG) in the definition of a cystocele (Cohen's $\kappa=0.90$ )

\begin{tabular}{lll} 
& UCG negative & UCG positive \\
\hline US negative & 37 & 2 \\
US positive & 0 & 13 \\
\hline
\end{tabular}

by means of ultrasound in 13 cases $(86.7 \%$ ) (Table 1$)$, whereas funneling in the UCG $(n=11)$ was detected by ultrasound in 10 cases $(90.9 \%$ ) (Table 2$)$. Funneling was detected by means of US in two additional cases that showed no funneling on UCG, whereas US was not
Table 2 Agreement between ultrasound (US) and urethrocystography (UCG) in the definition of funneling (Cohen's $\kappa=0.83$ )

\begin{tabular}{lll}
\hline & UCG negative & UCG positive \\
\hline US negative & 39 & 1 \\
US positive & 2 & 10 \\
\hline
\end{tabular}

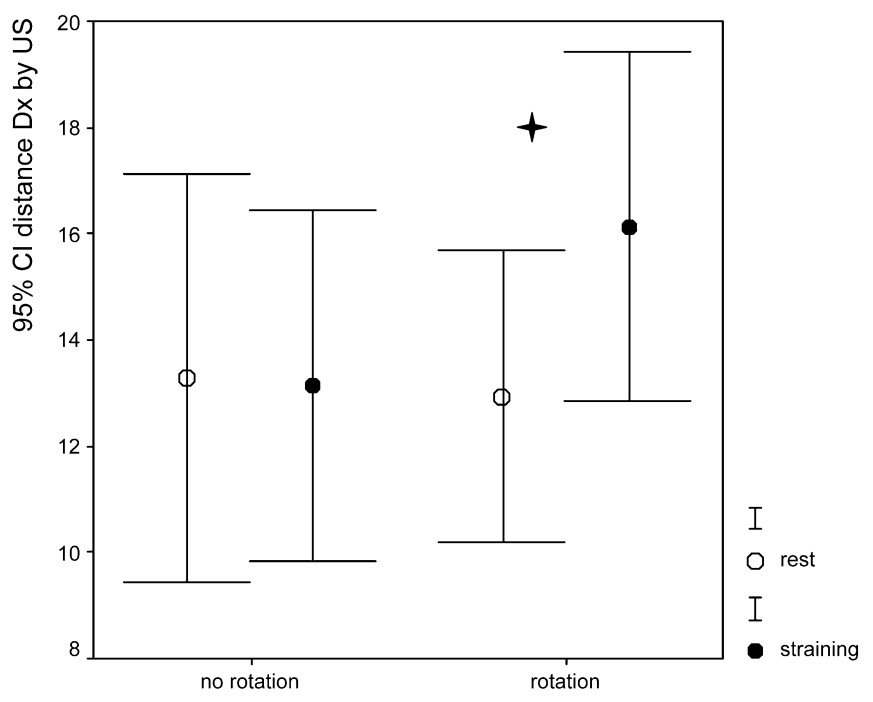

Fig. 5 Significant difference of distance $D_{x}$ in cases with a radiologically proven rotational descent $(\star p=0.009)$

more sensitive than UCG in the detection of a cystocele. We were unable to differentiate between distension and displacement cystoceles. In 24 cases a rotational descent of the bladder neck was diagnosed by UCG based on an increase in the angle of inclination $\alpha$ (data not shown). In these cases a significant increase of the distance $D_{x}$ from rest $(12.9 \pm 6.5 \mathrm{~mm})$ to straining $(16.1 \pm 7.8 \mathrm{~mm}$; $p=0.009$ ) was found by US. In contrast, in cases without rotation defined by UCG no such difference of $D_{x}$ between rest $(13.7 \pm 10.7 \mathrm{~mm})$ and straining $(13.1 \pm$ $8.2 \mathrm{~mm}$ ) could be observed (Fig. 5). In summary, a vertical descent should be indicated by a change in height $\mathrm{D}_{\mathrm{y}}$, whereas in cases with vertical and rotational descent both parameters $\mathrm{D}_{\mathrm{y}}$ and $\mathrm{D}_{\mathrm{x}}$ should be altered.

\section{Discussion}

The presence and severity of genuine stress incontinence depends on the resting urethral closure pressure and the pressure transmission, as well as the increase in abdominal pressure with stress [13]. Several methods, such as clinical and urodynamic examinations including UCG and US, are currently used to evaluate the underlying anatomical cause of incontinence. However, UCG as the former 'gold standard' is expensive, has the disadvantage of irradiation to the gonads, and in addition bears the risk of allergic reactions. Therefore, perineal ultrasound is increasingly performed, as it is a non-invasive method that has been shown to provide 
adequate information about the anatomical structures involved in urinary stress incontinence [4, 14].

In order to elicit standard values to compare measurements obtained by UCG and US, we, in contrast to other groups [15], have applied both methods to the same patient in the upright position to avoid any influence of posture [7]. We were able to describe the distance $\mathrm{D}_{\mathrm{y}}$ of the internal urethral os to the central line of the symphysis which corresponds to the radiological SCIPP line in a quantitative manner. We performed the UCG using $60 \mathrm{ml}$ of contrast medium, which is far less than the $300 \mathrm{ml}$ of saline used for perineal ultrasound, because it has been shown that the bladder volume has only little influence on the position of the bladder neck and the retrovesical angle $\beta[16,17]$. Data on the distances $\mathrm{H}$ and $\mathrm{D}_{\mathrm{y}}$ as well as the retrovesical angle $\beta$ determined by UCG and US, respectively, correlated very well at rest and straining, indicating that US was reliable and reproducible in our hands. Similar observations were made by some [15], but not all, authors $[4,5,18]$.

A distance $\mathrm{D}_{\mathrm{y}}$ of $11 \mathrm{~mm}$ between the internal urethral os and the central line of the symphysis corresponded to a bladder neck located on the SCIPP line, allowing a quantitative definition of any vertical descent by US. Values above that level would indicate a high position of the bladder neck in the pelvis, resulting in sufficient pressure transmission to ensure continence. In contrast, values less than $11 \mathrm{~mm}$ would indicate a low position with impaired pressure transmission, resulting most probably in urinary incontinence. This statement is also based on the results of the correlation of pressure transmission (DepQ) and height $D_{y}$. Here, the regression curve crosses the reference line at a height $D_{y}$ of $11 \mathrm{~mm}$. The higher the position of the bladder neck the more likely is a positive pressure transmission on to the urethra. To categorize the position of the bladder neck as above could assist in applying the proper management [2].

Data concerning the detection of funneling are contradictory in the literature, in that some report low [5] and others very good agreement between UCG and US [14], the latter being in accordance with our data. Reliable visualization of a cystocele with additional imaging of the cervix and vaginal vault by perineal ultrasound has also been demonstrated by others [3, 19], which is consistent with our findings. In contrast, it has been argued that the external probe would partially compress a cystocele, leading to an underestimation of its size [20].

Our data indicate that perineal ultrasound allows the correct diagnosis of any rotational descent of the bladder neck that results in a significant increase in distance $\mathrm{D}_{\mathrm{x}}$ corresponding to a rotational descent in the UCG. These observations are in line with the report by Dietz and Wilson [14], who found perineal ultrasound to be at least as sensitive as UCG for the detection of bladder rotation.

In summary, our data show that perineal ultrasound is a reliable tool for the anatomical evaluation of the bladder neck, and it allows an accurate diagnosis of funneling, cystocele and vertical and/or rotational descent. This is to our knowledge the first study to provide standard values for the vertical height of the internal urethral os based on perineal ultrasound.

\section{References}

1. Hodgkinson CP, Doub H, Keely W (1958) Urethrocystograms. Obstet Gynecol 1:1668

2. Petri E, Koelbl H, Schär GN (1999) What is the place of ultrasound in urogynecology? A written panel. Int Urogynecol J 10:262-273

3. Kohorn EI, Scioscia AL, Jeanty P, Hobbins JC (1986) Ultrasound cystourethrography by perineal scanning for the assessment of female stress urinary incontinence. Obstet Gynecol 68:269-272

4. Mouritsen L, Strandberg C (1994) Vaginal ultrasonography versus colpo-cysto-urethrography in the evaluation of female urinary incontinence. Acta Obstet Gynecol Scand 73:338-342

5. Schär GN, Köchli OR, Schüssler B, Haller U (1995) Perineal ultrasound for evaluating the bladder neck in urinary stress incontinence. Obstet Gynecol 85:220-224

6. Reddy AP, Delancey JOL, Zwica LM, Ashton-Miller JA (2001) On-screen vector-based ultrasound assessment of vesical neck movement. Am J Obstet Gynecol 185:65-70

7. Dietz HP, Clarke B (2001) The influence of posture on perineal ultrasound imaging parameters. Int Urogynecol J 12:104-106

8. Schär GN, Koelbl H, Merz E et al. (1996) Recommendations of the German association of urogynecology on functional sonography of the lower female urinary tract. Int Urogynecol J 7:105-108

9. Chen G-D, Su T-H, Lin LY (1996) Applicability of perineal sonography in anatomical evaluation of bladder neck in women with and without genuine stress incontinence. J Clin Ultrasound 25:189-194

10. Peschers UM, Fanger G, Schär GN et al. (2001) Bladder neck mobility in continent nulliparous women. Br J Obstet Gynaecol 108:320-324

11. Eberhard J (1986) Standardized measurement of urethral pressure with normal values in the diagnosis of stress incontinence. Geburtshilfe Frauenheilkd 46:145-150

12. Green TH (1962) Development of a plan for the diagnosis and treatment of urinary stress incontinence. Am J Obstet Gynecol 83:632-648

13. Walters MD, Newton ER (1993) Pathophysiology and obstetrics issues of genuine stress incontinence. In: Walters MD, Karram MM (eds) Clinical urogynecology. Mosby, St. Louis, pp 151-162

14. Dietz HP, Wilson PD (1998) Anatomical assessment of the bladder outlet and proximal urethra using ultrasound and videocystourethrography. Int Urogynecol J 9:365-369

15. Gordon D, Pearce M, Norton P, Stanton SL (1989) Comparison of ultrasound and lateral chain urethrocystography in the determination of bladder neck descent. Am J Obstet Gynecol 160:182-185

16. Mouritsen L, Bach P (1994) Ultrasonic evaluation of bladder neck position and mobility: the influence of urethral catheter, bladder volume, and body position. Neurourol Urodyn 13:637-646

17. Schär GN, Köchli OR, Schüssler B, Haller U (1996) Perineal ultrasound: determination of reliable examination procedures. Ultrasound Obstet Gynecol 7:347-352

18. Voigt R, Halaska M, Michels W, Voigt P, Martan A, Starker K (1994) Examination of the urethrovesical junction using perineal sonography compared to urethrocystography using a bead chain. Int Urogynecol J 5:212-214

19. Fink D, Schär GN, Perucchini D, Haller U (1996) Gynäkologische und perinealsonographische Untersuchung bei Frauen mit Stressinkontinenz - ein Vergleich. Ultraschall in Med 17:285-288 
20. Pajoncini C, Rosi P, Morcellini R, Constantini E, Guercini F, Porena M (1998) SUI and pelvic floor disease: the best ultrasound scanning approach. Neurourol Urodyn 17:371-372

\section{Editorial comment}

Although perineal ultrasound has been used extensively in urogynecology, standardized measurements of important anatomic landmarks have not been previously reported. Although the use of perineal ultrasound in the evaluation of incontinent women is controversial, this report better defines the position of the bladder neck in patients with stress incontinence. 